\title{
A MUDANÇA CLIMÁTICA E O IMPACTO NA PRODUÇÃO DE ALIMENTOS: Alguns Elementos de Análise da Realidade Brasileira e Argentina
}

\author{
http://dx.doi.org/10.21527/2176-6622.2020.54.32-43
}

Recebido em: 7/9/2020

Aceito em: 19/9/2020

Daniel Rubens Cenci

Pós-Doutor em Geopolítica Ambiental Latinoamericana. Doutor em Meio Ambiente e Desenvolvimento. Professor do Departamento de Ciências Jurídicas e Sociais e do Programa de Pós-Graduação - Mestrado em Direitos Humanos da Universidade Regional do Noroeste do Rio Grande do Sul - Unijuí. Coordenador da Linha de Pesquisa Direitos Humanos, Meio Ambiente e Novos Direitos. Coordenador do projeto de pesquisa CNPq "O direito ambiental no contexto da sociedade de risco: em busca da justiça ambiental e da sustentabilidade". http:// lattes.cnpq.br/2325516905314833. danielr@unijui.edu.br

Cristian Lorenzo

Doutor em Relações Internacionais (Universidad del Salvador, Argentina). Investigador-adjunto del Centro Austral de Investigaciones Científicas (Cadic - Conicet). Docente investigador-adjunto del Instituto de Ciencias Polares, Ambiente y Recursos Naturales (ICPA) - Universidad Nacional de Tierra del Fuego, Ushuaia, Tierra del Fuego, Argentina. http://lattes.cnpq.br/7967696680293051. clorenzo@conicet.gov.ar

\section{RESUMO}

O tema central do presente ensaio versa sobre a mudança climática e seu impacto na agricultura e pecuária brasileira e argentina, especialmente no que respeita à geopolítica da mudança climática e a produção de alimentos. A metodologia de trabalho foi a análise crítica de documentos e legislações que dão o suporte ao atual modelo de desenvolvimento da agricultura e pecuária nos monocultivos de grande extensão, com o objetivo de compreender o alcance da adoção de práticas voltadas para a produtividade de quantitativos e o abandono da dimensão qualitativa do modelo de desenvolvimento. O enfoque da sustentabilidade emerge no texto como princípio norteador da análise e como objetivo a ser buscado e trabalhado como resultado de práticas que devem ser introduzidas como condição sine qua non para a mitigação dos impactos da mudança climática e processos de adaptação. As possíveis conclusões apontam para a necessidade de mudanças na racionalidade econômica e adoção de práticas identificadas com a racionalidade ambiental, que primem por atender às necessidades alimentares da região, comprometidas com o bem-estar das gerações presentes e futuras, promovendo sustentabilidade.

Palavras-chave: Mudanças climáticas. Produção agrícola. Sustentabilidade.

\section{EL CAMBIO CLIMÁTICO Y EL IMPACTO EN LA PRODUCCIÓN DE ALIMENTOS: ALGUNOS ELEMENTOS DEL ANÁLISIS DE LA REALIDAD BRASILEÑA Y ARGENTINA}

\section{RESUMEN}

El tema central de este ensayo es sobre el Cambio Climático y su impacto en la agricultura y ganadería brasileña y argentina, especialmente en lo que respecta a la geopolítica del cambio climático y la producción de alimentos. Tomando como metodología de trabajo el análisis crítico de documentos y legislación que sustentan el modelo actual de desarrollo de la agricultura y ganadería, en monocultivos de gran escala, con el fin de comprender los alcances de la adopción de prácticas orientadas a la productividad de los procesos cuantitativos y el abandono de la dimensión cualitativa del modelo de desarrollo. El enfoque de la sostenibilidad emerge en el texto como principio rector del análisis y como objetivo a buscar y trabajar como resultado de prácticas que deben ser implementadas como condición sine qua non, para mitigar los impactos del cambio climático y los procesos de adaptación. Las posibles conclusiones apuntan a la necesidad de cambios en la racionalidad económica y la adopción de prácticas identificadas con la racionalidad ambiental, que se enfoquen en satisfacer las necesidades alimentarias de la región, comprometidas con el bienestar de las generaciones presentes y futuras, promoviendo la sostenibilidad.

Palabras clave: Cambio climático. Producción agrícola. Sustentabilidad.

\section{SUMÁRIO}

1 Introdução. 2 Dos riscos e incertezas ao Antropoceno. 3 Mitigação e adaptação às mudanças climáticas. 3.1 Estratégias no contexto da agricultura brasileira. 3.2 Estratégias no contexto da agricultura argentina. 4 Considerações finais. 5 Referências. 


\section{INTRODUÇÃO}

Nas últimas décadas, o aumento gradual da temperatura média do planeta e graves consequências para a humanidade e para a vida na Terra, tem sido tópico recorrente no cenário internacional. Embora a ciência contemporânea seja capaz de apontar os danos gerados pelo aquecimento global com inédita precisão, no âmbito político internacional não há reconhecimento e cooperação efetiva entre as nações para que o cuidado com o planeta seja compromisso de todos, com o consequente investimento nas políticas locais e mundiais de combate à mudança climática. Seus efeitos são nefastos em muitas áreas. No presente artigo, toma-se o enfoque do impacto destas mudanças na produção de alimentos e o comprometimento na segurança alimentar e alimentícia da humanidade como um todo. Com o objetivo de dar complementariedade ao conjunto de análises, toma-se o recorte brasileiro tanto dos principais impactos quanto das políticas locais e a (in)efetiva adesão aos projetos globais de combate à mudança climática e seus impactos.

O relatório científico divulgado pelo Painel Intergovernamental sobre Mudanças Climáticas - IPCC -, de enorme referência, divulgado no dia 8 de outubro de 2018 na Coreia do Sul, analisa as perspectivas de limitar o aquecimento global a $1,5^{\circ} \mathrm{C}$ em relação ao período pré-Industrial e desta necessidade crítica de uma ação climática urgente. Aprovado por 195 governos, o documento destaca a pequena janela de oportunidades que temos para sair do perigoso caminho de aquecimento em que o mundo se encontra. O Relatório Especial sobre o Aquecimento Global indica o aumento da temperatura acima de $1,5^{\circ} \mathrm{C}$. É o texto científico mais importante sobre a mudança climática, porquanto reúne centenas de especialistas dos diferentes países do mundo, construindo olhares críticos e fundamentados sobre os atuais contextos, e deve orientar as tomadas de decisão dos governos no aprimoramento de seus compromissos climáticos nacionais em relação ao Acordo de Paris, que vem sendo instituído desde sua edição em 2015. Este relatório cumpre um importante papel histórico construído mediante duras negociações entre governos após análise dos dados apresentados pelos cientistas, mas as promessas atuais dos países para reduzir as emissões são insuficientes para limitar o aquecimento global a $1,5^{\circ} \mathrm{C}$, com índices que representariam colapsos em muitos ecossistemas e grandes ameaças para a humanidade.

Anthony Giddens (2010), no livro A política da mudança climática, aponta as causas do aquecimento global, seus possíveis efeitos e quais as soluções crê serem cabíveis na mudança de cultura necessária para que as condições climáticas não culminem numa nova grande crise ambiental com o colapso da sobrevivência humana.

Segundo o autor, as principais consequências desse aquecimento seriam: o derretimento da água congelada na cobertura de montanhas e em geleiras, a elevação dos oceanos em razão desse derretimento e da expansão térmica da água, o aumento da quantidade de nuvens, vapor de água e, consequentemente, da quantidade de chuvas, alteração das características do ambiente em diferentes regiões, entre elas o deslocamento de chuvas e ausência delas, resultando em cheias ou secas como acontecimentos extremos causados pela mudança climática. As consequências traduzem-se nos impactos em múltiplas dimensões, como altos índices de chuvas em reduzido período de tempo, agravado pelas impermeabilizações, resultando em inundações e deslizamentos com grandes impactos nas cidades, bem como a alteração de clima e umidade e a consequente modificação das condições atmosféricas com grande impacto no processo de produção agrícola e pecuária, definindo, assim, um novo momento para a produção agrícola e a segurança alimentar nas distintas regiões, entre outras.

O presente artigo apoia-se na metodologia do tipo exploratória, com análise de algumas obras de pesquisadores do tema e dados dos principais documentos internacionais, em especial estudos do IPCC, pela densidade e amplitude de seus documentos, e trata do tema das mudanças climáticas, tecendo considerações a respeito do viés socioeconômico e seus impactos para as políticas públicas que demandarão transformações de adaptabilidade aos novos contextos que a mudança climática exige, no sentido de dar sustentabilidade aos sistemas econômicos, sociais e ambientais.

\section{DOS RISCOS E INCERTEZAS AO ANTROPOCENO}

Os avanços referentes à coleta de dados climáticos têm facilitado a apuração do impacto das mais diversas atividades diárias contemporâneas e sua contribuição para o aumento da temperatura média do planeta. 0 Painel Intergovernamental sobre Mudanças Climáticas das Nações Unidas (Intergovernamental Panel on Climate Change - IPCC) foi criado em 1988 e é, atualmente, referência nos estudos das variações do clima no planeta. 
Os estudos constataram que o aumento da temperatura do planeta tem acelerado o degelo em regiões de congelamento permanente, nas quais a superfície gelada constitui uma espécie de capa protetora de grandes quantidades de vegetação decomposta, que, se exposta, irá liberar na atmosfera grande quantidade de dióxido de carbono. Outra causa do aumento da temperatura é o aquecimento das águas oceânicas, que as tornam mais ácidas e também aumentam o nível da emissão de gases geradores do efeito estufa, além de causar dano - que não se tem ao certo a extensão, mas sabe-se que é catastrófico - na fauna e flora marinha (IPCC, 2007).

Por mais que o aquecimento descontrolado da temperatura do planeta apresente desde já resultados preocupantes, mesmo que não apocalípticos, e a sociedade os conheça, as massas populacionais não sentem a necessidade de mudar os hábitos correntes nem de tomar posição a respeito do que acontece. Revela-se uma certa preocupação e curiosidade sobre as novas realidades, sem, entretanto, entender a gravidade da crise e distante de adotar atitudes mitigatórias. Aparenta uma não consciência dos riscos, da gravidade da crise ambiental e uma percepção de que "alguém" poderá ser afetado e "alguém" deverá tomar atitudes, mas sempre na perspectiva de que "alguém" são outros. Os riscos são iminentes, no entanto não geram comoção social suficiente para que o mercado modifique suas praxes e passe a adotar, como regra, as energias limpas, nem preste a devida atenção nas práticas de consumo cotidianas. Flui um comportamento de lucrar sobre as catástrofes, sobre os eventos extremos, sobre a desgraça alheia.

Os números são contundentes. Segundo o relatório do IPCC (2007), entre 1970 e 2004 as emissões globais de $\mathrm{CO}_{2}, \mathrm{CH}_{4}, \mathrm{~N}_{2} \mathrm{O}, \mathrm{HFCs}$, PFCs e $\mathrm{SF}_{6}$, ponderadas pelo seu potencial de aquecimento global, aumentaram em 70\% (24\% entre 1990 e 2004), passando de 28,7 para 49 gigatoneladas de equivalentes de dióxido de carbono (GtCO2-eq)2. As emissões desses gases aumentaram em taxas diferentes. As emissões de $\mathrm{CO}_{2} \mathrm{cresce}$ ram em cerca de 80\% entre 1970 e 2004 (28\% entre 1990 e 2004) e representaram 77\% do total das emissões antrópicas de gases de efeito estufa em 2004.

Esta medição do impacto das ações humanas mensurada entre 1970 e 2004, representa bem a mudança radical das práticas humanas e sua capacidade de gerar impacto no ambiente. Neste texto nos apoiamos nestes dados para identificar a principal causa da mudança climática, conforme milhares de estudos comprovam, em oposição àqueles que preferem apoiar-se apenas em dúvidas ou alguns poucos estudos, para seguir negando a dimensão antropogênica da crise atual. Assim, reconhecendo que haverá sempre na ciência um grau de incertezas, é com as clarividências que estamos trabalhando, porque sobre estas também podemos atuar, enquanto a dúvida serve apenas para aqueles que se beneficiam dela, e a grande maioria acumula impactos negativos.

De acordo com Giddens (2010), falta de consideração aos riscos inerentes às mudanças climáticas tem a ver com o "desconto do futuro". Os maiores danos causados pela alteração da temperatura estão situados no futuro, por isso geram menos preocupação para a sociedade em geral do que os problemas do presente. A maioria das pessoas reconhece o problema do aquecimento global como real, porém não possui motivação para ativamente lutar contra suas causas, preferindo uma recompensa imediata, mesmo que isso signifique abrir mão de, futuramente, ser recompensado com algo melhor.

Uma série de políticas sobre mudança do clima estão sento criadas mundo afora, especialmente na área da segurança energética e desenvolvimento sustentável, primeiro por ser uma área de grande contribuição para a emissão de gases estufa, segundo porque trata-se de novo produto de mercado, a energia limpa. Tais políticas têm sido parcialmente eficazes na redução das emissões de gases de efeito estufa em diferentes setores e em muitos países. A escala dessas medidas, contudo, ainda não foi grande o suficiente para fazer frente ao aumento das emissões globais, quiçá, pelo modelo de crescimento econômico que requer a cada dia mais energia e mais barata, em nome da geração de produtos com potencial de concorrência entre indústrias e, ao final, submetendo-se à lógica de mercados.

Os combustíveis fósseis têm papel central no desenvolvimento econômico desde a Revolução Industrial e do avanço das técnicas de extração, respectivamente. $O$ crescimento da economia, porém, perde sentido no momento em que deixa de considerar os aspectos de bem-estar, social e individual. Neste ponto, os visíveis efeitos do aquecimento global demonstram que, apesar de se possuir reservas de combustíveis fósseis para as próximas décadas, não é recomendável que a utilização destes se mantenha como a principal fonte energética, pela sua condição limitada e pelas suas características e potencial altamente impactante e contaminante. 
Igualmente, o carvão representou a ascensão da indústria no modelo que se apresenta hoje em dia, reduzindo consideravelmente a necessidade do emprego de força humana na produção em massa. No contexto social estadunidense, a energia gerada por um ser humano, em contraponto à gerada pelo combustível que alimenta as mais diversas máquinas usadas no dia a dia, chega-se à conclusão de que o cidadão médio, para manter seu estilo de vida, usa, por meio de combustíveis, a energia produzida pelo equivalente a 150 seres humanos. Do ponto de vista energético é um combustível seguro, por outro lado, do ponto de vista ambiental tem potencial devastador, seja pela fuligem, seja pelos gases que emite quando da queima. Apesar de conhecermos seus impactos nefastos ao ambiente, o carvão segue atualmente entre as principais fontes de energia da China, país hegemônico na atividade industrial internacional.Neste contexto, Jeremy Rifkin (2013) mostrou que o preço do barril de petróleo atingiu, em julho de 2008, o preço de US\$187, seu pico. 0 ocorrido deve-se ao fato de que a cada dia mais os produtos da cadeia industrial são feitos e/ou movidos por combustíveis fósseis. Além de ser matéria-prima de uma grande quantidade de combustiveis automotivos, é também ingrediente de fertilizantes, tintas, borrachas, plástico, entre outros. O petróleo movimenta grandes quantidades de capital, fato que dificulta o questionamento da dependência do mercado acerca deste; no entanto, crises enfrentadas pelo aumento do preço do barril abrem espaço para que se possa revisar as prioridades da indústria e reavaliar a segurança energética proporcionada pelo combustível fóssil em questão.

A importância de examinar o impacto dos combustíveis fósseis na economia mundial reside no fato de que, enquanto os lucros provenientes da exploração de atividades que contribuem com o aquecimento global superarem os lucros de qualquer outro setor da economia, será cada vez mais difícil adotar novos meios de geração de energia, como a eólica, termoelétrica, das ondas do mar, solar, biomassa, sem uma intervenção radical estatal globalizada. De outro lado, a mudança apenas na legislação e na tributação não trará os resultados almejados, pelo menos não a longo prazo, uma vez que os governos dos países democráticos possuem tempo determinado no poder, sendo necessário que a preocupação com a mudança climática transcenda os ideais políticos de cada vertente, além de o engajamento popular representar grande força nos debates. Neste sentido, Giddens propõe, entre outras, duas dimensões fundamentais: convergência política e convergência econômica.

A convergência política concerne na valoração positiva da política da mudança climática quando comparada a outros objetivos políticos. Diz respeito ao alcance desta política no âmbito social e à capacidade que tem de inovar e influenciar o modo de vida atual (GIDDENS, 2010). Por exemplo, políticas públicas que culminam na diminuição da emissão de carbono, tais como diminuição do uso de automóveis individuais. Já a convergência econômica trata das vantagens econômicas auferidas por aqueles que busquem inovar no sentido de aliar a redução da emissão com as táticas de mercado. Ou seja, evitar que empresas sejam prejudicadas na competição, que é o mercado, se buscar incorporar na sua filosofia de trabalho métodos que não contribuem com o aquecimento do planeta, ou com grande responsabilidade na mitigação deste impacto. Acredita, porém, que abstenções individuais não constituem o caminho mais eficaz para fazer frente ao aumento gradual da temperatura.

O problema deve transcender a dimensão do individualismo, em se tratando de buscar mudanças que afetarão diretamente a existência do ser humano no planeta. Igualmente não se pode rotular a luta contra a emissão de gases geradores do efeito estufa como sendo ideologicamente de esquerda ou de direita. Neste sentido, surgem os acordos internacionais. O mais recente deles, o Acordo de Paris de 2015, no seu artigo 20 estabeleceu os seus principais objetivos, sendo eles:

(a) Manter o aumento da temperatura média global bem abaixo de $2^{\circ} \mathrm{C}$ em relação aos níveis pré-industriais, e envidar esforços para limitar esse aumento da temperatura a $1,5^{\circ} \mathrm{C}$ em relação aos níveis pré-industriais, reconhecendo que isso reduziria significativamente os riscos e os impactos da mudança do clima; (b) Aumentar a capacidade de adaptação aos impactos negativos da mudança do clima e promover a resiliência à mudança do clima e um desenvolvimento de baixa emissão de gases de efeito estufa, de uma maneira que não ameace a produção de alimentos; e (c) Tornar os fluxos financeiros compatíveis com uma trajetória rumo a um desenvolvimento de baixa emissão de gases de efeito estufa e resiliente à mudança do clima. 


\section{Direito自

Este representou o primeiro acordo de caráter efetivamente global que diz respeito a como o mundo lidará com a mudança climática, reunindo, na ocasião, 195 países. O Brasil, ao prestar o compromisso de cumprir o acordo, vinculou-se às metas de reduzir a emissão de carbono em $37 \%$ até 2025 e 43\% até 2030, tendo como referencial a quantidade emitida no ano de 2005 (BRASIL, 2015).

O debate sobre o controle de gases estufa é preocupante. O Protocolo de Quioto, de 1997, estabelece obrigações quantificadas de limitação ou redução diferenciadas de emissões para os países industrializados e os países não industrializados e diferentes obrigações em relação à mudança do clima. A própria Convenção reconhece que a parcela das emissões globais, originárias dos países em desenvolvimento, crescerá para que eles possam satisfazer suas necessidades sociais e econômicas. Em muitos desses países, as emissões podem aumentar em consequência das políticas de redução da pobreza, por exemplo, levar eletricidade às áreas rurais ou remotas. O objetivo comum, contudo, é um futuro em que o desenvolvimento se baseie em soluções menos intensivas em carbono, com base em critérios de sustentabilidade, o que requereria investimentos dos países desenvolvidos nos países em desenvolvimento, bem como transferência de tecnologias ambientalmente adequadas. Mesmo com documentos construídos em bom nível, sua efetivação nunca foi realidade pelo não cumprimento, especialmente a destinação dos recursos, que deveria ser realizada pelos países industrializados.

Segundo o Protocolo, o Brasil não tem o dever de estabelecer limites de emissões dos gases estufa, porém esta obrigatoriedade é estabelecida no Acordo de Paris. Conforme este acordo, o país assume a meta de redução de $37 \%$ nas emissões até 2025 , tendo como ponto de partida as emissões de 2005 e a possível redução de $43 \%$ das emissões até 2030.

A análise do alcance da crise e colapso ambiental é preocupante. Também seus impactos na vida das pessoas e na economia de maneira geral. Dados do Fórum Global Humanitário (2009) mostravam que 325 milhões de pessoas sofriam em decorrência das mudanças climáticas, das quais 315 mil morrendo a cada ano por suas graves consequências; as perdas materiais anuais aproximavam-se de U\$S 125 bilhões; dos mais de 6 bilhões de seres humanos na Terra em 2010, hoje 7 bilhões, 4 bilhões estão ameaçados de alguma forma pelos efeitos das mudanças climáticas, e 500 milhões enfrentam risco extremo. De acordo com esse relatório, os efeitos das mudanças climáticas constituem o operar de uma crise silenciosa, que assume as formas de fome ou doenças, mas também se mostra em ciclones, inundações ou ondas de calor, impactando mais fortemente as populações economicamente mais desfavorecidas.

A humanidade modificou o Planeta Terra de forma tão intensa que entramos no antropoceno, a época em que humanos substituíram a natureza como a força ambiental dominante na Terra. Como característica marcante da vida no antropoceno, verifica-se o aumento da frequência dos fenômenos climáticos extremos. Isso já está acontecendo. $\mathrm{O}$ ano de 2015 bateu uma série de recordes climáticos nunca antes registrados pela ciência. Registros de que foi o ano mais quente da história, com cerca de 1으 mais quente do que a temperatura do planeta antes da industrialização. Também é o ano que mais se registraram eventos extremos, como furacões, tornados e vendavais, das categorias mais fortes no mundo. Secas como as que acontecem em São Paulo e no Nordeste brasileiro, e tempestades como as que castigam o Sul do Brasil, serão mais frequentes, conforme já projetavam estudos do IPCC (2007).

A Organização para a Alimentação e Agricultura (FAO) alerta para outros aspectos diretamente vinculados à produção de alimentos, como a perda da biodiversidade, cujos impactos podem causar perdas significativas na produção de alimentos se não forem tomadas providencias imediatamente. Por um lado, pela perda direta da qualidade do solo, das águas e do ar, e, por outro, impactos indiretos, consequência dessas mudanças, como perda da biodiversidade em geral, tornando os processos menos férteis, nas florestas, campos, manguezais, águas de maneira geral. Tais impactos apontam para perdas superiores a $50 \%$ das plantas, $11 \%$ das aves, mais de $20 \%$ dos insetos polinizadores, e começam a comprometer a capacidade dos sistemas produtivos, sobremaneira a produção de alimentos.

Apesar do conjunto de impactos, estudos comprobatórios e evidências da grave crise ambiental e seus impactos, é possível que os sinais e evidências da mudança climática em curso sejam banalizados, provocando uma certa aceitação - como se fosse fatalidade - dificultando a elaboração e a instituição das necessárias políticas preventivas. Esse comportamento paradoxal é apontado por Giddens (2010) como um sinal de que a mudança climática ainda não é tangível no cotidiano das pessoas. Resulta daí que as pessoas não agem e, assim, 
a dinâmica social na qual estão inseridas faz com que somente comecem a agir para enfrentar os efeitos das mudanças climáticas quando já forem visíveis, o que faz com que seus impactos sejam, então, possivelmente catastróficos.

É neste sentido que se analisa o colapso ambiental e as possibilidades mitigatórias e de adaptação à nova realidade, porquanto, se trata de uma mudança multidimensional, socialmente estrutural, dos processos de produção ao consumo de cada cidadão, pois mudanças para sair de uma crise estrutural, nunca antes imaginada, exigirá alterar as lógicas históricas de crescimento, desenvolvimento, prosperidade e bem-estar, numa revisão da relação do homem com a natureza, com o manejo nos processos produtivos e com a compreensão de que o planeta é, efetivamente, uma casa comum e requer atitude de todos os atores.

\section{MITIGAÇÃO E ADAPTAÇÃO ÀS MUDANÇAS CLIMÁTICAS}

Tomando por referência o papel central na produção de alimentos para a região da América Latina, bem como da capacidade e volumes de exportação do Brasil e da Argentina, construímos, a seguir, algumas análises referentes às políticas de desenvolvimento, produção de alimentos e os diferentes impactos das políticas aplicadas no setor agropecuário. Estes elementos permitem compreender alguns fundamentos do risco produzido e não assumido pelo denominado agronegócio na região, e, ao mesmo tempo, revelam as escolhas mercadológicas e os confrontos geopolíticos regionais e globais no debate sobre segurança alimentar e desenvolvimento.

\subsection{Estratégias no Contexto da Agricultura Brasileira}

As múltiplas manifestações da alteração do clima requerem responsabilidade e aprofundamento das análises para compreender, com a profundidade que o tema exige, os impactos no processo de produção agrícola e pecuária no contexto brasileiro.

Reconhecer que falar em mudanças do clima é uma maneira suave de falar do aquecimento global, da crise socioambiental multifacetada, do agravamento dos impactos e da utilização da palavra relativamente recente no trato do tema da mudança climática, que é o colapso dos sistemas naturais e sistemas produtivos de alimentos, justifica rememorar que o comprometimento da biodiversidade, do empobrecimento gradativo e acelerado do solo, da poluição da água e do ar, na confrontação com o aprofundamento das desigualdades, da superficialidade e fragilidade dos sistemas democráticos e da grande lacuna que se abre na distribuição da riqueza, tendo um crescimento demográfico desordenado, agrava o quadro de miséria no mundo.

Diante de tal realidade e da dificuldade de criação de medidas efetivas de mudanças nas práticas causadoras do aquecimento global, cabe abrir um novo período de análises para entender como é possível mitigar os impactos e construir capacidades de adaptabilidade ao período que estamos batendo à porta. Para além das catástrofes diárias que o mundo enfrenta, a vulnerabilidade urbana e rural, decorrente da realidade climática, requer novas condutas.

A nova realidade tem apresentado dificuldades de efetivação das metas de combate às causas da emissão dos gases estufa, especialmente na produção agrícola e pecuária, por meio do crescente desmatamento e das queimadas, respectivamente práticas vinculadas à produção de soja e da criação de gado. Tais práticas têm comprometido as metas 2020 e 2030 de estabilização e redução da emissão de gases estufa pelo Brasil, ocasionando, em primeiro lugar, um desrespeito aos compromissos assumidos internacionalmente, notadamente no Acordo de Paris, e, em segundo lugar, uma certa legitimação de práticas arcaicas no modelo de desenvolvimento que tem se mostrado perdulário com as temáticas ambientais, e em terceiro lugar perdas de biodiversidade geral que, apesar de evidentes, pouco são tomadas em consideração nos cálculos das perdas econômicas.

Assim, ante o aumento da pobreza e, portanto, da dependência interna de alguns países e mesmo externa entre países, cabe indagar se a região latino-americana, especialmente o Brasil, está preparado para adaptar-se a um processo de construção de outras alternativas ao modelo posto.

Nos sistemas de produção, baseados em práticas agrícolas de alto uso de produtos químicos, especialmente agrotóxicos, desenvolvidas em monoculturas de grande extensão, promovendo o avanço do desmatamento como estratégia de ampliar índices de produção, um avanço de produtividade com descontrole 
químico que tem dado causa à contaminação de águas, do solo, do ar, destruindo ecossistemas, no uso de energias não renováveis, que, fundamentalmente, seguem dando lastro ao aquecimento global, entre outros, a indagação é se queremos e se temos decisão política para instituir outros modelos de produção, respeitosos com a natureza e com o ritmo de produção e produtividade suficientes para garantir segurança alimentar, sistemas que respeitem a estrutura agroflorestal e as dinâmicas da natureza, com a radicalidade necessária para falar em sistemas sustentáveis.

Um estudo denominado "Aquecimento Global e a nova Geografia da Produção agrícola no Brasil", realizado por pesquisadores da Empresa Brasileira de Pesquisa Agropecuária (Embrapa) e da Universidade Federal de Campinas (Unicamp) (ASSAD; PINTO, 2008), apresenta importantes informações acerca de como o aquecimento global pode alterar a geografia da produção agrícola do Brasil. 0 estudo avaliou os impactos que o aquecimento global deverá causar às principais culturas agrícolas do país nas próximas décadas.

Foram estudadas as culturas do café, algodão, arroz, cana-de-açúcar, feijão, girassol, mandioca, milho e soja, além das pastagens e gado de corte. Segundo o estudo, nas próximas décadas as mudanças do clima devem ser tão intensas que poderão ocasionar modificações na geografia da produção agrícola nacional, chegando ao ponto de municípios, que hoje figuram entre os grandes produtores de grãos, não o serem mais a partir de 2020, agravando-se a cada década com perdas significativas. De maneira geral, os pesquisadores observaram que o aumento de temperatura pode provocar uma diminuição de regiões aptas para o cultivo dos grãos e a migração da capacidade de produção dentro do território brasileiro, devendo ocorrer uma transferência de produção com a migração de cultivos para regiões que apresentem condições climáticas mais propícias às culturas. Isso implicaria o desaparecimento da cultura da mandioca na região do semiárido, com alto impacto na segurança alimentar, uma vez que é a principal fonte de alimentação humana em todo o nordeste brasileiro, e a diminuição do plantio do café no Sudeste, consequência da baixa condição de sobrevivência desta cultura na região. Por outro lado, a Região Sul passaria por uma grande mudança de cultivos, pois ao sofrer uma redução do risco de geadas se tornaria propícia ao plantio de mandioca, de café e de cana-de-açúcar. A região, no entanto, não seria mais apropriada ao cultivo da soja, por estar mais sujeita a estresses hídricos.

Trata-se, todavia, de cenários projetados a partir de uma condição de vulnerabilidade diversa apresentada, o que requer diferentes sistemas ou formas de produção agrícola que possam apresentar distintos graus de enfrentamento da vulnerabilidade aos efeitos da mudança climática, e podem ser, eventualmente, atenuados por intermédio do desenho de estratégias de adaptação apropriadas.

No que respeita à emissão dos gases de efeito estufa no Brasil, as atividades agropecuárias representam o maior desafio, pois emite-se o dobro da média global para esse tipo de emissão (FEPAM, 2010). Um inventário preliminar, entretanto, ainda não mostra o efeito das queimadas e desmatamento provenientes da expansão agrícola. O desmatamento, contudo, tem sido apontado como responsável por aproximadamente $60 \%$ das emissões dos gases de efeito estufa no Brasil e vinculado ao fato de que $75 \%$ das emissões de gás carbônico do país são provenientes das queimadas na Amazônia (MARENGO, 2007).

Observa-se um grave paradoxo, por um lado. Um modelo de desenvolvimento expansionista e com base nas monoculturas, requer áreas de terra mais amplas para aumentar a produção, enquanto esta expansão ocorre às custas da supressão de matas, especialmente a floresta amazônica, promovendo dois danos graves, sendo um a redução das florestas e outro a promoção de queimadas com altos índices de emissão de gases de efeito estufa. No caso brasileiro, agrava-se o quadro pelas posições adotadas pelo governo no âmbito federal, pois apresenta grande adesão ao discurso do agronegócio assentado nas práticas referidas e mesmo pela dificuldade de aceitar os dados científicos referentes ao aquecimento global e à interferência humana neste processo.Assim, o campo para pensar políticas agrícolas e agrárias que harmonizem os processos produtivos, com apoio aos sistemas agroflorestais com perspectivas de sustentabilidade, não faz parte dos recursos orçamentários no atual contexto. Ao contrário, a área ambiental tem sofrido frequentes e sucessivos cortes de recursos financeiros, redução de capacidade de trabalho em nome de ajustes estruturais, esvaziando este debate desde as pesquisas nos espaços acadêmicos até o corte de orçamento para a efetivação das políticas que vinham estimulando as iniciativas agroecológicas, orgânicas, solidárias, integradas, de âmbito familiar e local.

A lógica de avaliação do crescimento econômico pelo crescente aumento dos índices de produção constitui uma dimensão importante para o contexto geral, porém há um conjunto expressivo de contradições. Os impactos ambientais a médio e longo prazos estão comprometidos. $O$ descolamento das preocupações com 
o equilíbrio ambiental demonstra que ainda não está incorporado o conjunto das dimensões indispensáveis para pensar a sustentabilidade. A noção e o compromisso político na dimensão intergeracional e na necessária cooperação entre os povos para consecução dos objetivos do milênio, denotam um distanciamento comprometedor entre a crise e o colapso climático ambiental e a urgência de mudanças. Prepondera a quebra de compromissos políticos locais e globais pela opção político-ideológica de governos, distanciando-se dos propósitos de nação e de país com fundamental importância na região da América Latina, bem como sua pujança e importância pelos cenários internacionais.

É bem verdade que não é apenas um problema do Brasil e tampouco latino-americano. Temos assistido descompromissos com os Objetivos de Desenvolvimento Sustentável (ODS) nos diferentes temas e nas distintas regiões do mundo. Apresenta-se um quadro desafiador de reconstrução de compromissos comuns pela sustentabilidade. A lógica de mercado é insuficiente para estabelecer os compromissos ambientais que o contexto exige, bem como as atuações governamentais não têm dado conta de estabelecer limites satisfatórios nas práticas de produção, tanto industriais quanto agropecuárias. Veja-se o tema da oferta de produtos agrotóxicos proibidos em vários países e permitidos por vários países latino-americanos, destacadamente o Brasil. Não poderá a ciência e a política permanecerem inertes ou silenciadas pelo poder econômico mercantil que avança descontroladamente em grande parte das nações e imaginarmos um resultado adequado do ponto de vista das responsabilidades socioambientais. Casos como dos Estados Unidos da América, imitados pelo Brasil. As bancadas de poderes legislativos, pressionadas pelos grupos econômicos multinacionais, se submetem a laudos, nem sempre reconhecidos pela ciência, ou já reconhecidamente problemáticos pela comunidade acadêmica internacional, mas que por lobbies econômicos, vinculados ao denominado agronegócio, acabam aprovados e postos em circulação para consumo.

Os dados da realidade brasileira demonstram crescimento vertiginoso do uso das técnicas químicas como única prática para os processos de produção agropecuários. Veja-se alguns dados.

\section{Gráfico 1 - Número de agrotóxicos aprovado por ano no Brasil}

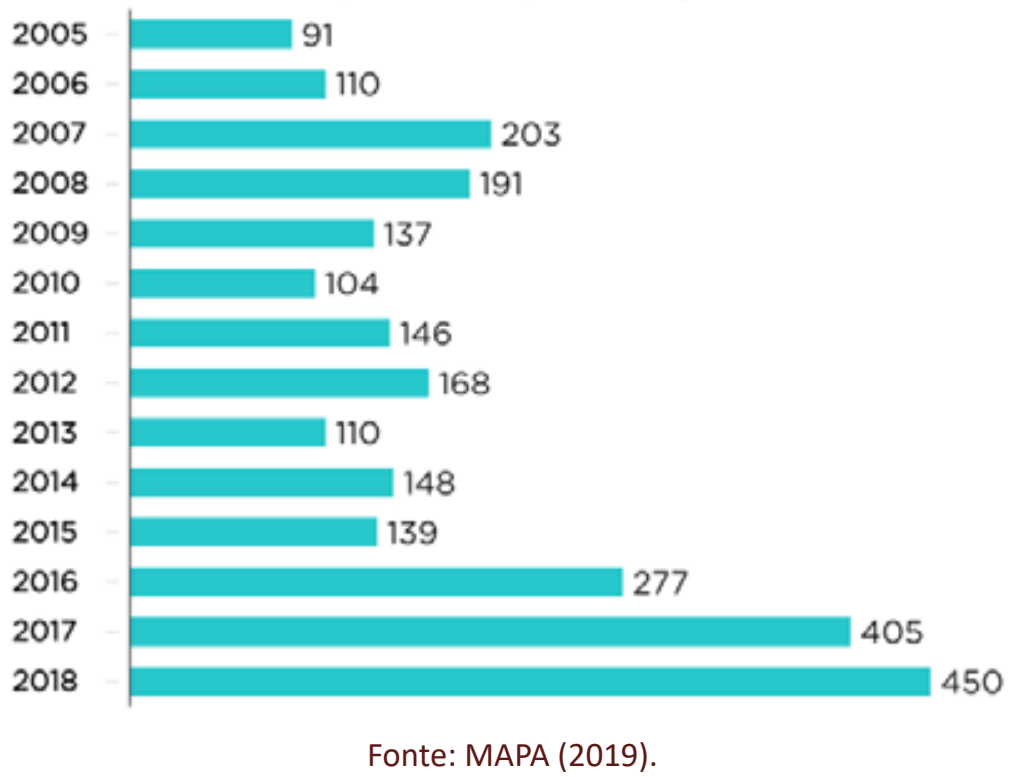

Segundo o Ministério da Agricultura, até 4 de março de 2019 o governo de Jair Bolsonaro (PSL) havia liberado 74 produtos relacionados a agrotóxicos, 58 deles já formalizados mediante publicação no Diário Oficial da União. Agora, o país passa a ter mais de 2.000 produtos agrotóxicos liberados para comercialização. De acordo com dados do Ministério da Agricultura, Pecuária e Abastecimento, em 2018, durante o governo de Michel Temer (MDB), foram aprovados 450 registros, um recorde histórico. O Ministério da Agricultura afirmou ao jornal Folha de São Paulo que o aumento nos registros vem ocorrendo em razão de "uma maior agilidade da Anvisa nas análises toxicológicas". A Agência Nacional de Vigilância Sanitária (Anvisa) é responsável por avaliar o grau de toxicidade dos produtos. 
As análises apontam para a necessidade de retomada dos debates sobre o tema da produção de alimentos no Brasil. Por outro lado, as possibilidades de delimitar as práticas de usos deliberados de produtos químicos restam profundamente fragilizadas, porquanto, fica clara a opção governamental do Brasil pela liberdade ao mercado, no sentido de não estabelecer controles e responsabilidades claras em prol dos consumidores, favorecendo apenas os negócios.

\subsection{Estratégias no Contexto da Agricultura Argentina}

A Argentina assinou o Acordo de Paris em 2015. Desde então, uma série de ações relacionadas foram realizadas. O referido acordo entrou em vigor em 1 o de setembro de 2016 , conforme Lei Nacional número 27.270/2016, pela qual foi criado o Gabinete Nacional de Mudanças Climáticas, o Compromisso Federal de Mudanças Climáticas, a Contribuição Nacional revisada (NDC) foi preparada, os planos de ação setoriais começaram a ser debatidos e foram elaborados um Plano Nacional de Mitigação e o Plano Nacional de Resposta às Mudanças Climáticas. Desde dezembro de 2019, a Argentina possui uma lei nacional sobre a mudança climática. Juntas, essas ações respondem pelas prioridades e decisões tomadas pelos governos argentinos (Mauricio Macri 2015-2019 e Alberto Fernández, desde 2019), que afetam o presente e o futuro do país, bem como pelos compromissos internacionais assumidos como Estado argentino. Ainda será necessário um desenho jurídico e institucional para a Argentina planejar seu comportamento futuro em diferentes setores da economia, bem como quais serão suas contribuições no âmbito regional e planetário. Tudo isso apresenta uma questão central na redução de emissões de gases estufa. Essa é uma primeira aproximação que requer mais investigações.

Um dos aspectos associados à assinatura do Acordo de Paris pela Argentina é sua articulação com a política climática na esfera doméstica. Aqui reside um dos seus desafios políticos. Isso inclui várias negociações entre atores em âmbito nacional para definir os compromissos que cada setor assumirá para a contabilidade nacional, referindo-se às emissões de gases emitidos para a atmosfera. Na mitigação, por exemplo, os setores em que essas reduções entram em jogo são Transporte, Indústria, Agricultura e Energia. Além disso, essas negociações referem-se a um processo que não está associado a uma revisão do pedido atual. Outro componente associado ao plano doméstico está relacionado ao estabelecimento de marcos regulatórios no âmbito das províncias.

Essa escala de análise é interessante em um país com as características e estrutura federal como a Argentina, mostrando que a perspectiva internacional não é necessariamente uma questão distante da vida das pessoas. Pelo contrário, os compromissos internacionais assumidos pelo Estado argentino estão relacionados à vida de seus habitantes. Em relação a este tópico, a contabilidade climática supramencionada abre uma discussão sobre modelos de desenvolvimento no plano provincial, em que, da mesma forma que no âmbito nacional, envolve propostas de interesse de atores, de diferentes setores e com diversas capacidades. Este é um processo que ainda está em construção, em aberto portanto.

Com relação ao impacto na mudança climática na Argentina, deve-se notar que ela não se manifesta de maneira homogênea em todo o seu território. Isso é importante por causa do impacto potencial que ela tem na agricultura, que é o setor que estamos enfatizando neste trabalho. Conforme indicado na comunicação da Argentina para a Convenção do clima, projetam-se cenários que aumentam as temperaturas altas e as chuvas extremas, como um elemento comum e transversal. Embora haja margens de incerteza associadas a essas estimativas, projeta-se que as maiores mudanças seriam relativas ao aumento da temperatura e não às chuvas. Além disso, em termos geográficos, o aumento projetado de temperatura é maior no norte do que no sul do país. Essa variabilidade, associada às mudanças climáticas, estabelece uma realidade que requer uma abordagem abrangente das políticas públicas, porque o que está em jogo é a vida das gerações presentes e futuras na Argentina.

Com relação ao setor agrícola, na Argentina, segundo a Direção Nacional de Estatísticas Externas - Indec -, o complexo de exportação mais importante, em 2019, foi a soja, com uma participação de 26\% (16.943 miIhões de dólares) do total. Nesse ano, suas principais parcerias comerciais foram a União Europeia (US \$ 3404 milhões), a Ásia (US \$ 3301 milhões), a China (US \$ 3,198 milhões) e a Índia (US \$ 1659 milhões). É possível conhecer a origem provincial das exportações associadas ao complexo de soja. O mesmo relatório indica que, de todas as exportações de 2019 (65.115 milhões de dólares), a região econômica do Pampa foi a mais relevante em termos de troca comercial em toda a Argentina, com 16.377 milhões de dólares. Essas estatísticas 
mostram que, no perfil de inserção internacional da Argentina, o complexo de exportação de soja é predominante, e também indica que está concentrado em uma série de províncias da Argentina, localizadas no centro e no centro-leste do país. Mostra, ainda, que existe uma dependência focada na China e na Índia, países que importam uma quantia maior, em termos de milhões de dólares, para todos os países que compõem a União Europeia e a Ásia juntos.

Se o setor agrícola está ligado às mudanças climáticas na Argentina, é necessário levar em conta a capacidade setorial de emitir gases de efeito estufa na atmosfera. Das emissões totais consideradas no país, a agricultura representa 38\% (138.934 MtCO2eq) incluídas agricultura, pecuária e silvicultura. Esses dados mostram que se trata de um setor da economia que, apesar de gerar divisas para o Estado argentino, ao mesmo tempo é um dos setores mais poluentes do território. Um modelo de desenvolvimento que atualmente apoia a maneira de se inserir no mercado agroalimentar internacional que o Estado argentino possui e que deve ser questionado.

Compreender a ordem agrícola atual na Argentina exige levar em consideração sua dinâmica temporal. Nesse sentido, é nos anos 90 que esse modelo começa a surgir, cuja configuração exigia uma série de componentes, como decisões de políticas públicas que favoreciam a desregulamentação do setor agrícola, a introdução de sementes geneticamente modificadas e o uso de glifosato. Nesse modelo, os beneficiários passaram pelas empresas dedicadas à exportação de soja, muitas multinacionais. Assim, segundo Miguel Teubal ([2006?]).

A política mãe que possibilitou uma importante mudança institucional na política agrária e que serviu de base para essas transformações foi o decreto de desregulamentação de 1991. Com base nessa medida, foram eliminados os organismos que existiam entre os anos 1930 e este ano. O Conselho Nacional de Grãos, o Conselho Nacional de Carnes, a Direção Nacional do Açúcar etc., organizações cujo objetivo era regular a atividade agrária (por exemplo, manter os preços de apoio à produção de cereais em apoio aos produtores de pampas). Desde então, o setor agrícola argentino se tornou um dos menos regulamentados do mundo, sujeito como nenhum outro, aos altos e baixos da economia mundial. Essas e outras medidas adotadas durante os anos 90 contribuíram para o desaparecimento de inúmeras fazendas, principalmente as que possuíam menos de 200 hectares. Outro marco importante a favor do modelo da soja geneticamente modificada - GM, foi o lançamento da semente GM Roundup Ready (RR) no mercado em 1996. Desde então, o agronegócio de grandes empresas do sistema agroalimentar se consolidou no país. Foi assim que o Estado favoreceu o modelo de soja. Esse suporte foi estendido ao domínio inicial. Embora tradicionalmente houvesse um regime legal que permitisse aos produtores agrícolas reproduzir suas próprias sementes, surgiram pressões de grandes empresas internacionais de sementes (principalmente Monsanto) para limitar essa prerrogativa, forçando o produtor agrícola a pagar royalties pelo seu uso e proibindo a possibilidade de reproduzi-lo mesmo para uso próprio.

Esse modelo ainda persiste e, diante dos efeitos das mudanças climáticas na Argentina, é necessário prestar atenção a alguns sinais que fazem parte do presente e que estão criando novas possibilidades. Nesse sentido, até agora não se percebe que isso mudará no curto ou no médio prazos. De qualquer forma, isso não significa que seja o melhor possível em termos de sustentabilidade ambiental. Recentemente, o ministro do Meio Ambiente e Desenvolvimento Sustentável da Argentina, Juan Cabandié, no âmbito de uma reunião virtual da Comissão de Meio Ambiente e Desenvolvimento Sustentável do Senado, questionou um dos pontos centrais do modelo de produção dominante do setor, afirmando que o glifosato, ou veneno, contamina os lençóis freáticos e o rosto das crianças é pulverizado em escolas rurais e centros urbanos. Existem mortes por glifosato. Se fizéssemos um exame de sangue, ficaríamos muito alarmados. Se fizéssemos um estudo com glifosato no prato de comida, ficaríamos alarmados. Infelizmente, isso não tem geografia. Isso atinge todos os lugares. A contaminação tem a característica de não ter lugar físico.

Diante dessas afirmações sobre o uso de agroquímicos, setores predominantes da agricultura intensiva, com base no uso de herbicidas, se opõem.

Para avaliar as possibilidades de mudar o modelo de produção, supramencionado, é necessário dar conta de um fato conjuntural: hoje estamos vivendo uma pandemia que afeta todos os setores da economia argentina. Nesse contexto, a revisão de um modelo de desenvolvimento parece improvável. De qualquer forma, é importante mencionar que não é a última alternativa possível. Como exemplo, diferentes municípios argentinos estavam trabalhando na construção de um paradigma alternativo, baseado na ideia de agricultura sem agrotóxicos. Essa forma de produção alternativa à de escala industrial é aquela construída em espaços como a 
Rede Nacional de Municípios e Comunidades que promovem a Agroecologia - Renama. Desvendar a consolidação da forma produtiva dominante no âmbito agrícola, intimamente relacionada à inserção internacional da Argentina, requer tempo e, principalmente, uma situação favorável, no espaço político e econômico. Em todo esse contexto, é auspicioso que uma maneira de conceber a agricultura tenha sido institucionalizada, como alternativa à predominante. $\mathrm{A}$ isto se acrescenta que a Argentina possui experiências agroecológicas, que têm visibilidade internacional. Nesta linha de questionamento do modelo predominante, o canal de televisão alemão Deutsche Welle (também conhecido por seu acrônimo DW) publicou, em 12 de fevereiro de 2019, em seu site, um vídeo, no qual revelava uma leitura político-ecológica, clareando quais são os impactos que prevalecem na forma atual de produção e enfatizando o futuro possível que está em construção pela agroecologia.

A Argentina é o terceiro maior produtor mundial de alimentos e um dos principais exportadores de soja GM e seus derivados. Estima-se que 400 milhões de litros de agroquímicos são despejados por ano em suas lavouras, substâncias que por deriva ou aplicação direta também atingem alimentos, os quais, como o glifosato, são questionados por seus efeitos negativos na saúde humana. A sociedade civil começa a se mobilizar contra a agricultura industrial e o uso de agroquímicos (DEUTCHE VELLE, 2020).

Enquanto isso, as prioridades associadas às mudanças climáticas estão vinculadas a outras que também fazem parte da agenda política do Estado argentino.

Embora enfrente-se um problema em escala global, cada um dos países tem seus próprios desafios no âmbito interno. A Argentina, assim como o Brasil, é um país muito rico em recursos naturais e com altos graus de desigualdade interna, com uma alta porcentagem da população abaixo da linha da pobreza. Soma-se a isso uma realidade estrutural financeira e conjuntural das economias, profundamente impactadas pela pandemia da Covid-19.

É para o conjunto desses elementos que o futuro dos países exige pensar em uma série de variáveis, dentre as quais, sem dúvida, a mudança climática, como uma questão transversal a todas as suas políticas públicas. As possibilidades, portanto, de construir um futuro sustentável, em um contexto de mudança climática, exigem a revisão da forma dominante de produção e o incentivo a alternativas que beneficiem a maioria das gerações atuais e futuras.As mudanças climáticas, nesse sentido, podem servir como um fator externo que exige mudanças para se adaptar a um futuro que, embora esteja sendo construído, ainda é incerto. Em um período de grandes avanços tecnológicos, da cultura da inovação e da adoção das novas tecnologias, é fundamental retomar princípios do meio ambiente que orientam desde o direito até as práticas produtivas, numa ecologia com biodiversidade preservada, com as estruturas de sustentação da vida tomadas em harmonia com os eixos da terra, água, ar, energia e calor, como condições de reprodução da vida.

\section{CONSIDERAÇÕES FINAIS}

É urgente discutir os rumos do modelo de desenvolvimento do tempo presente. Os grandes avanços tecnológicos não equacionaram os problemas da pobreza e da miséria. Num tempo de acelerados processos produtivos, geramos produtos e mal podemos entender como as escolhas políticas ainda permitem que persista milhões de pessoas em estado de necessidade e morrendo, pois o acesso aos bens lhe é sonegado. Entre as conquistas do mundo natural e o domínio da natureza pela foça humana, impera uma noção de poder que induz a civilização no que diz respeito ao uso da terra e aos cuidados com o meio em que habita. O Planeta Terra, ao longo de sua extensa cronologia, foi palco de grandes extinções. Sempre, no entanto, recuperou-se no intervalo de poucos milhões de anos, embora as populações nele residentes tenham tragicamente encontrado seu fim.

A crise atual mostra-se mais social que ambiental. Por um lado, porque a coesão social sobre a crise ambiental é muito frágil e acaba por potencializar a própria crise climática, pois as possibilidades de ações tornam-se fragmentadas e frágeis. Neste sentido, cabe repensar os eixos tomados para as análises que possam promover as mudanças capazes de mitigar efetivamente os impactos da mudança climática e realização das adaptações necessárias que permitam seguir vivendo o bem-estar no presente e preservando o ambiente para o bem-estar das futuras gerações, promovendo a sustentabilidade. 
Mitos de fundamentar nos números da economia é o suficiente para satisfazer as necessidades humanas; é aposta numa verdade parcial e frágil. O discurso do desenvolvimentismo carrega sempre um propósito de que a exuberância da economia derramará benefícios para satisfazer às necessidades de todos. Assiste-se, entretanto, processos de acumulação de terras, de riquezas, de condições de vida, que, por um lado, produzem a opulência, e, por outro, a carência. Neste sentido, resta claro o argumento sempre presente de que, para atender às necessidades de todos, é preciso expandir usos da terra, da água e do ambiente em geral. Acreditamos, porém, que, sem garantir acesso à educação de qualidade para todos, serviços de saúde, segurança, trabalho com remuneração justa, seguiremos reproduzindo versões equivocadas de sociedade.

Outro campo que necessita avançar é a própria democracia, garantindo espaços de participação e construções coletivas de voluntariado social do conjunto da sociedade, para que analise e defina as ações capazes de solucionar os problemas. O Estado precisa garantir justiça social, não necessariamente pela sua atividade, mas pela ação inteligente e reguladora do modelo de sociedade e desenvolvimento. Enfim, não se trata apenas de problemas ecológicos e ambientais, mas socioambientais, reestabelecendo equações de equilíbrio do homem com a natureza, do uso respeitoso do ambiente como casa comum, para a qual cada um dedica o melhor de seus conhecimentos e ações para o bem-estar presente e futuro.Neste sentido, o sentimento de onipotência, característico do homo sapiens, deve ser reposicionado no campo dos saberes. Agregar às pautas políticas o enfrentamento das atividades causadoras do aquecimento global não é uma questão apenas de salvar o planeta, uma vez que a humanidade não é detentora do poder necessário para destruí-lo, mas de garantir que a qualidade de habitabilidade para seres humanos perdure por mais tempo do que o presente e revele compromisso com as gerações futuras no mais profundo sentido da sustentabilidade.

\section{REFERÊNCIAS}

ACORDO DE PARIS. 2015. Disponível em: http://www.mma.gov.br/images/arquivos/clima/convencao/indc/Acordo_Paris.pdf. Acesso em: 24 jul. 2018.

ARGENTINA. Lei 27.270 de 01/09/2016. Disponível em: https://www.argentina.gob.ar/normativa/nacional/ley-27270-265554. Acesso em: 25 ago. 2020.

ARGENTINA. Lei 27.520, 19/12/2019. Ley de Presupuestos Mínimos de Adaptación y Mitigación al Câmbio Climático Global. Acesso em: 25 ago. 2020.ASSAD, E. D.; PINTO, H. S. (coord.). Aquecimento global e cenários futuros da agricultura brasileira. São Paulo: Embrapa; Unicamp, 2008. 84 p.

BRASIL. República Federativa do Brasil. Pretendida contribuição nacionalmente determinada para consecução do objetivo da convenção-quadro das nações unidas sobre mudança do clima. 2015. Disponível em: http://www.mma.gov.br/images/arquivos/clima/convencao/indc/BRASIL_iNDC_portugues.pdf. Acesso em: 24 jul. 2018.

COSTA, L. C. Mudanças climáticas: vulnerabilidade na agricultura. Belo Horizonte, 2007. Disponível em: http://www.ecolatina. com.br/pdf/anais/6.../LuizClaudioCosta.pdf. Acesso em: 16 mar. 2019.

DEUTCHE VELLE. Disponível em: https://www.dw.com/es/los-guardianes-de-la-tierra-agroecolog\%C3\%ADa-en-argentina/ av-48309045?maca=es-EMail-sharing. Acesso em: 28 ago. 2020.

FEPAM. Fundação Estadual de Proteção Ambiental Henrique Luis Roessler. Inventário de GE. Apresentação da metodologia. 7 maio 2010. Disponível em: www.fepam.rs.gov.br/ Documentos_e_PDFs/GEE/InventarioGEE.pdf. Acesso em: 28 mar. 2020.

FÓRUM GLOBAL HUMANITÁRIO. 2009. Disponível em: https://refunitebrasil.wordpress.com/2009/06/24/refugees-united-participa-do-forum-humanitario-global-2009/.

GIDDENS, Anthony. A política da mudança climática. Rio de Janeiro: Zahar, 2010. 314 p.

IPCC. Intergovernamental Panel on Climate Change. Organization. 2007. Disponível em: http://www.ipcc.ch/organization/organization.shtml. Acesso em: 28 mar. 2019.

MARENGO, J. A. O impacto das mudanças climáticas no Brasil. CPTEC/INPE. 2007. Disponível em: http://mudancasclimaticas. cptec.inpe.br/ rmclima/pdfs/Mudanca_clima_Brasil-IPCC_2001.pdf. Acesso em: 15 mar. 2019.

MAPA. Ministério da Agricultura, Pecuária e Abastecimento. 2019. Disponível em: https://www.nexojornal.com.br/expresso/2019/03/11/Como-est\%C3\%A1-a-libera\%C3\%A7\%C3\%A3o-de-agrot\%C3\%B3xicos-no-governo-Bolsonaro. Acesso em: 2 maio 2019.

RENAMA. Rede Nacional de Municípios e Comunidades que promovem a Agroecologia. Disponível em: http://www.renama. org/. Acesso em: 22 ago. 2020.

RIFKIN, Jeremy. Energizing the third industrial revolution. 2013. Disponível em: https://www.energy.siemens.com/us/pool/hq/ energy-topics/publications/living-energy/pdf/issue-08/Industrial-Revolution-Rifkin-Living-Energy-8.pdf. Acesso em: 24 jul. 2018.

TEUBAL, Miguel. Expansión de la soja transgénica en la Argentina. [2006?]. Disponível em: https://www.vocesenelfenix.com/ content/expansi\%C3\%B3n-de-la-soja-transg\%C3\%A9nica-en-la-argentina. 